\title{
Association of Lipid Abnormalities with High-Sensitivity C - reactive Protein in Patients Treated with Atorvastatin
}

Farhana Ferdousi ${ }^{1}$, Mohammad Abdul Hai Siddique ${ }^{2,3}$, Syed Muhammad Kamaluddin', Muhammad Saiedullah ${ }^{1 *}$ and Liaquat Ali',4

${ }^{1}$ Department of Applied Laboratory Sciences, Bangladesh University of Health Sciences, Dhaka, Bangladesh

${ }^{2}$ Department of Biochemistry and Cell Biology, Bangladesh University of Health Sciences, Dhaka, Bangladesh

${ }^{3}$ Department of Biochemistry and Molecular Biology, University of Rajshahi, Rajshahi-6205, Bangladesh

${ }^{4}$ Honorary professor, Department of Biochemistry and Cell Biology, Bangladesh University of Health Sciences (BUHS), Dhaka, Bangladesh

\begin{abstract}
Dyslipidemia and subclinical inflammation are the major determinants of cardiovascular disorders. For the management of dyslipidemia, statin is used and claimed to be effective in the reduction subclinical inflammation. In this study, lipidemic and subclinical inflammatory status in patients treated with stable statin (atorvastatin) therapy were evaluated in 111 Bangladeshi subjects. Lipid parameters and marker of subclinical inflammation ( $h s C R P$ ) were measured by enzymatic endpoint techniques and by immunoturbidimetric method. Persistent single dyslipidemia is prominent for low-density lipoprotein (LDL) cholesterol $(57.66 \%)$, followed by hypertriglyceridemia $(55.86 \%)$, high-density lipoprotein (HDL) cholesterol dyslipidemia (54.06\%), and hypercholesterolemia (20.72\%). Regarding combined lipid abnormalities, elevated triglyceride (TG) combined with elevated LDL cholesterol was most frequent $(35.13 \%)$. Persistent multiple combined lipid abnormalities for 3 lipid parameters (low HDL cholesterol, elevated LDL cholesterol and elevated TG) was observed for $19.82 \%$ subjects. Persistent subclinical inflammation ( $h s C R P$ $>3.0 \mathrm{mg} / \mathrm{l})$ was found to be high $(36.94 \%)$, followed by moderate risk $(33.33 \%)$ and low risk for CVDs $(29.73 \%)$. hsCRP showed positive association total cholesterol (TC) and negative association with LDL cholesterol and HDL cholesterol. But after adjustment for age, sex, BMI, diabetes mellitus and duration of statin therapy, only HDL cholesterol showed significant inverse association with $h s \mathrm{CRP}(\beta=-0.314, p=0.016)$. This study revealed that single or multiple combined dyslipidemia persists in subjects treated with statin. Large proportions of the subjects had subclinical inflammation which is inversely associated with HDL cholesterol on adjusting confounders.
\end{abstract}

Keywords: Dyslipidemia; Subclinical inflammation; Atorvastatin; High-density lipoprotein cholesterol; High sensitivity C-reactive protein

\section{Introduction}

Cardiovascular diseases (CVDs), the leading causes of death in the world are rising rapidly in low- and middle-income countries [1]. CVDs are the most prevalent cause of morbidity and mortality among patients with type1 or type2 diabetes [2]. In general, patients with diabetes aggregate other comorbidities such as obesity, hypertension, and dyslipidemia which also contribute to increase the risk for CVDs [3]. Disorder in lipid metabolism is one of the main determinants of cardiovascular risk. The primary target of lipid management is to achieve low-density lipoprotein (LDL) cholesterol at goal [4]. Statin therapy lowers the risk of cardiovascular events by reducing plasma cholesterol levels, and practice guidelines for patients with known cardiovascular disease emphasize the importance of reaching target goals for lowdensity lipoprotein (LDL) cholesterol [5]. For the management of dyslipidemia, statins or fibrates are commonly used. Statins (HMGCoA reductase inhibitors) reduce CVD risk by approximately $23 \%$ per every $1 \mathrm{mmol} / \mathrm{l}(\sim 39 \mathrm{mg} / \mathrm{dl})$ low-density lipoprotein (LDL) cholesterol lowering [6]. Atorvastatin, at doses ranging from $2.5 \mathrm{mg}$ to $80 \mathrm{mg}$ daily, can reduce LDL by $25 \%$ with the lowest dose and up to $60 \%$ with the maximal dose [7]. Beside lipid parameters, high sensitivity C-reactive protein $(h s \mathrm{CRP})$ - an inflammatory cytokine and an independent predictor of CVD [8-13] is claimed to be reduced by statin treatment [14-19]. The US Food and Drug Administration approved a new use for statin therapy among those with elevated $h s$ CRP and one additional risk factor, and the Canadian Cardiovascular Society recently issued new national guidelines indicating that statin therapy should be offered to those at "intermediate risk" who have elevated levels of $h s \mathrm{CRP}$, even if LDL-C levels are low [20]. Though proven befit of statin on CVD risk, patients with dyslipidemia remains at high risk for cardiovascular events even after LDL cholesterol, blood pressure and $\mathrm{HbA}_{1 \mathrm{c}}$ target have been achieved [21]. For example, in the DYSIS-Netherlands study, majority $(71.77 \%)$ of patients receiving statin therapy fail to reach normal levels for lipid parameters [22]. However, no study has yet been carried out in Banglalee population regarding persistent dyslipidemia and subclinical inflammation in patients treated with statin.

On the basis of that finding and in the effort to address the clinical issues outlined above, we used a commercial assay to measure $h s \mathrm{CRP}$ and simultaneously measured plasma levels of serum total cholesterol, low-density lipoprotein (LDL) cholesterol, and high-density lipoprotein (HDL) cholesterol. Under this context, this study was undertaken to explore the status of lipid abnormalities and subclinical inflammation in patients on stable statin (atorvastatin) therapy in this population. We also sought to determine whether the measurement of markers of inflammation in addition to standard screening of lipid levels might provide a clinically useful method for improving overall prediction of the risk of cardiovascular events.

*Corresponding author: Muhammad Saiedullah, Department of Applied Laboratory Sciences, Bangladesh University of Health Sciences, Dhaka, Bangladesh, Tel: +8801911570497; E-mail: md.saiedullah@gmail.com

Received June 02, 2015; Accepted June 18, 2015; Published June 23, 2015

Citation: Ferdousi F, Siddique MAH, Kamaluddin SM, Saiedullah M, Ali L (2015) Association of Lipid Abnormalities with High-Sensitivity C - reactive Protein in Patients Treated with Atorvastatin. J Diabetes Metab 6: 564. doi:10.4172/21556156.1000564

Copyright: (c) 2015 Ferdousi F, et al. This is an open-access article distributed under the terms of the Creative Commons Attribution License, which permits unrestricted use, distribution, and reproduction in any medium, provided the original author and source are credited. 


\section{Methods}

\section{Study designs and population}

This cross-sectional study was conducted in the department of Clinical Biochemistry, Bangladesh Institute of Health Sciences (BIHS), Dhaka, Bangladesh during the period of January 2012 to June 2012. Subjects (111) were selected purposively from the out-patient department of BIHS according to inclusion-exclusion criteria. Subjects receiving statin monotherapy during last 3 months (apparently healthy adults) were included and patients with serious comorbid diseases (infection, stroke, myocardial infarction, major surgery, malabsorption, severe allergy, cancer, severe illness, liver dysfunction, chronic kidney disease (CKD), pregnancy, edema, oral contraceptive users, steroid or non-steroidal anti-inflammatory drugs users were excluded. Informed consent was taken before data collection and clinical examination. Before specimen collection history of diabetes, hypertension, blood pressure reading, height, weight were recorded. Data regarding habit of smoking, current medication or others were also recorded.

\section{Anthropometric measurements}

Anthropometric indices included height and weight. All the individuals were measured wearing light clothing without shoes and hats. Height was measured to the nearest $0.1 \mathrm{~cm}$ using a portable stadiometer and weight was measured to the nearest $0.1 \mathrm{~kg}$ using calibrated platform scales.

\section{Blood pressure measurement}

Blood pressure was measured to the nearest $1 \mathrm{~mm} \mathrm{Hg}$ with mercury sphygmomanometers using standard recommended procedures [23]. Two readings each of systolic and diastolic blood pressures were recorded, and taken at 5 minutes intervals. The average of two readings was used in the data analysis. If two of the measurements differed by more than $5 \mathrm{~mm} \mathrm{Hg}$, an additional reading was taken.

\section{Diabetes mellitus measurement}

Diabetes mellitus is characterized by recurrent or persistent hyperglycemia, and is diagnosed by WHO diagnostic criteria for diabetes mellitus [24]. Blood glucose level is measured using the glucose oxidase method. The fasting blood glucose level, which is measured after a fast of 8 hours, is the most commonly used indication of overall glucose homeostasis. The metabolic response to a carbohydrate challenge is conveniently assessed by a postprandial glucose level drawn 2 hours after a meal or a glucose load. First-morning sample were collected fasting 10-12 hours prior to going in for blood collection.

\section{Clinical measurements}

Blood samples were obtained from the antecubital vein with the subject sitting comfortably in a chair in a quiet room and transfused into vacuum tubes containing EDTA in the morning after an overnight fasting period. After separation, blood samples were centrifuged for 10 minutes at $3000 \mathrm{rpm}$ to obtain serum. Then serum was aliquoted into 2 microtubes, one preserved for lipid profile measurements and another was preserved at $-20^{\circ} \mathrm{C}$ for $h s \mathrm{CRP}$ estimation until analysis.

Serum total cholesterol, triglyceride concentrations were measured by end point technique using Dimension ${ }^{\circledR}$ clinical chemistry system (Siemens Healthcare Diagnostics Inc. USA) using reagents (Cat. No. DF27, Siemens Healthcare Diagnostics Inc. USA). HDL cholesterol levels was measured by an fully automated reagent format Dimension ${ }^{\mathbb{R}}$ clinical chemistry system (Siemens Healthcare Diagnostics Inc. USA) and LDL cholesterol concentrations in serum were calculated by
Friedewald's formula [25]. hsCRP concentrations were determined immunotubidimetric by using BN ProSpec ${ }^{\circledR}$ system (Siemens Healthcare Diagnostics Products GmbH, Germany).

\section{Statistical methodology}

Statistical analysis was performed using MedCalc ${ }^{\circledR}$ version 11.4 for Windows, STATISTICA version 8.0 for windows. All data were expressed as mean \pm SD (standard deviation) and/or percentage (\%) as appropriate.

We used Pearson correlation to show the relationship of the difference between the two parameters to the mean of the two measurements [26]. To analyse that the factors affect the changes of $h s \mathrm{CRP}$, a multivariate linear regression model was used to determine $\log (h s \mathrm{CRP})$ as a function of baseline $\log (h s \mathrm{CRP})$, gender, body mass index, systolic blood pressure, diastolic blood pressure, blood lipids, serum glucose (fasting blood glucose). Standardized $\beta$ were used to compare the strength of the effect of each independent variable on the $\log (h s \mathrm{CRP}$ ), which with the largest standardized $\beta$ (independent of the sign) has the strongest effect. Relationships between log ( $h s \mathrm{CRP})$ and these variables were also assessed by multiple regression analysis. The level for statistical significance was set at 0.05 .

\section{Results}

\section{Clinical characteristics}

Total 111 dyslipidemic subjects were included in this study to explore residual lipid abnormalities and subclinical inflammation on statin therapy. All the subjects used statin (atrovastatin, $10 \mathrm{mg}$ per day) with a mean duration of $2.35 \pm 2.55$ years. Characteristics of the study subjects are shown in Table 1 of the total subjects, 41 (37\%) had BMI $\leq$ $25 \mathrm{Kg} / \mathrm{m}^{2}, 47$ (42\%) had BMI: $25-30 \mathrm{Kg} / \mathrm{m}^{2}$ and 23 (21\%) had BMI $>30$ $\mathrm{Kg} / \mathrm{m}^{2}$.

\section{Correlation of $h s C R P$ with the lipid measurements}

Table 2 shows the correlation of lipid parameters with $h s \mathrm{CRP}$ in the study subjects. Twenty-three $(20.72 \%)$ of the study subjects had elevated serum total cholesterol (>200 mg/dl), 60 (54.06 \%) had low

\begin{tabular}{|c|c|c|c|}
\hline Parameters & Mean $\pm S D / N u m b e r$ & $\beta$ value & $p$ value \\
\hline Age (years) & $53 \pm 11$ & 0.114 & 0.2877 \\
\hline Gender (Male/Female, \%) & $55 / 56(50 / 50)$ & 0.138 & 0.5501 \\
\hline Body mass index $\left(\mathrm{Kg} / \mathrm{m}^{2}\right)$ & $26.8 \pm 4.5$ & 0.094 & 0.3901 \\
\hline Hypertension & \multicolumn{3}{|c|}{$78(71 \%)$} \\
\hline $\begin{array}{l}\text { Systolic blood pressure } \\
\qquad(\mathrm{mm} \mathrm{Hg})\end{array}$ & \multicolumn{3}{|c|}{$124 \pm 13$} \\
\hline $\begin{array}{l}\text { Diastolic blood pressure } \\
\qquad(\mathrm{mm} \mathrm{Hg})\end{array}$ & \multicolumn{3}{|c|}{$81 \pm 8$} \\
\hline Diabetes mellitus (\%) & $92(83 \%)$ & 0.099 & 0.4864 \\
\hline Smoker & $15(14 \%)$ & 0.098 & 0.5784 \\
\hline \multicolumn{4}{|l|}{ Lipid status (mg/dl) } \\
\hline Total cholesterol & $23(>200 \mathrm{mg} / \mathrm{dl}) / 20.72 \%$ & 0.733 & 0.1075 \\
\hline HDL cholesterol & $60(<35 \mathrm{mg} / \mathrm{dl}) / 54.06 \%$ & -0.314 & 0.0157 \\
\hline LDL cholesterol & $62(>70 \mathrm{mg} / \mathrm{dl}$ ) / $55.86 \%$ & -0.602 & 0.1491 \\
\hline Triglyceride & 39 (>150 mg/dl) / 35.13\% & 0.012 & 0.9469 \\
\hline \multicolumn{4}{|c|}{ Medication } \\
\hline $\begin{array}{l}\text { Duration of atorvastatin } \\
\text { therapy (years) }\end{array}$ & $2.35 \pm 2.55$ & -0.166 & 0.0912 \\
\hline
\end{tabular}

Table 1: Baseline clinical characteristics of study subjects. 
Citation: Ferdousi F, Siddique MAH, Kamaluddin SM, Saiedullah M, Ali L (2015) Association of Lipid Abnormalities with High-Sensitivity C - reactive Protein in Patients Treated with Atorvastatin. J Diabetes Metab 6: 564. doi:10.4172/2155-6156.1000564

Page 3 of 5

\begin{tabular}{|c|c|c|}
\hline Parameters & $\boldsymbol{\beta}$ value & $\boldsymbol{p}$ value \\
\hline Age & 0.114 & 0.2877 \\
\hline Sex (male) & 0.138 & 0.5501 \\
\hline BMI & 0.094 & 0.3901 \\
\hline DM & 0.099 & 0.4864 \\
\hline Smokers & 0.098 & 0.5784 \\
\hline Duration of atorvastatin therapy & -0.166 & 0.0912 \\
\hline Triglyceride & 0.012 & 0.9469 \\
\hline Total cholesterol & 0.733 & 0.1075 \\
\hline LDL cholesterol & -0.602 & 0.1491 \\
\hline HDL cholesterol & -0.314 & 0.0157 \\
\hline
\end{tabular}

Table 2: Correlation of $h s \mathrm{CRP}$ with the lipid measurements.

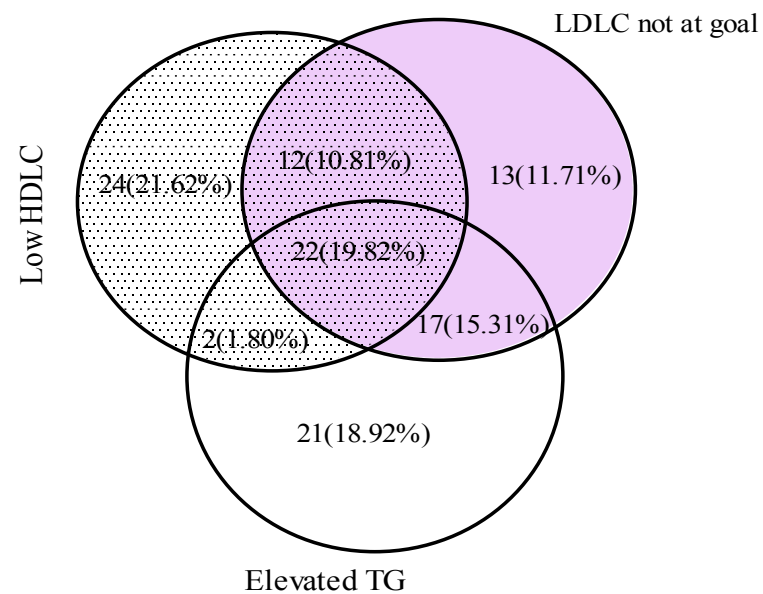

Figure 1: Distribution of single and multiple combined lipid abnormalities among the study subjects.

serum HDL cholesterol, of them $26.13 \%$ male had HDL cholesterol $<35 \mathrm{mg} / \mathrm{dl}$ and $27.93 \%$ female had HDL cholesterol $<40 \mathrm{mg} / \mathrm{dl}$. Elevated LDL cholesterol was observed for 62 (55.86 \%) of the total subjects in which subjects with both hypertension and diabetes mellitus constituted $44.14 \%$ (LDL cholesterol $>70 \mathrm{mg} / \mathrm{dl}$ ), only hypertensive constituted $3.60 \%$ (LDL cholesterol $>100 \mathrm{mg} / \mathrm{dl}$ ), only diabetic subjects constituted $8.11 \%$ (LDLC>100 $\mathrm{mg} / \mathrm{dl}$ ) and nondiabetic normotensives contributed $1.80 \%$ (LDL cholesterol $>130 \mathrm{mg} / \mathrm{dl}$ ). Distribution of single and multiple combine lipid abnormalities are presented in Figure 1.

\section{Variability of $h s \mathrm{CRP}$ and other risk factors by single lipid abnormality}

Figure 2 shows distribution of mixed lipid and $h s$ CRP risk factors in the study subjects. Thirty-three (29.73\%) of the participants had low risk for CVD ( $h s \mathrm{CRP}<1.0 \mathrm{mg} / \mathrm{dl}), 37$ (33.33\%) had moderate risk for CVD (hsCRP: $1.0-3.0 \mathrm{mg} / \mathrm{dl}$ ) and 41 (36.94\%) had high risk for CVD. Of the high risk subjects $(h s \mathrm{CRP}>3.0 \mathrm{mg} / \mathrm{dl}) 14(12.61 \%)$ subjects were male and $27(24.32 \%)$ were female. Of the total study subjects, 27 (24.32\%) had combined risk for HDL cholesterol and $h s$ CRP (both low HDL cholesterol and elevated $h_{s} \mathrm{CRP}$ ) (Figure 2A); 22 (19.82\%) had combined risk for LDL cholesterol and $h s$ CRP (elevated LDL cholesterol with elevated $h_{s} \mathrm{CRP}$ ) (Figure 2B) and 22 (19.82\%) had combined TG and $h s \mathrm{CRP}$ risk factors (Elevated TG with elevated $h s \mathrm{CRP}$ ) (Figure 2C). Elevated $h s \mathrm{CRP}$ was higher (45\%) in subjects with low HDL cholesterol followed by $35.5 \%$ in subjects with elevated TG and $34.3 \%$ in subjects with elevated LDL cholesterol.

\section{Multivariable analysis}

Multiple linear regression analysis considering $h s$ CRP as dependent variable and lipid parameters as independent variables showed that $h s \mathrm{CRP}$ was positively associated with total cholesterol $(\beta=1.136, p=0.010)$ and negatively associated with LDL cholesterol $(\beta=-0.954, \mathrm{p}=0.016)$ and HDL cholesterol $(\beta=-0.299, \mathrm{p}=0.020)$. But after adjustment for age, sex, BMI, diabetes mellitus and duration of statin (atrovastatin) therapy, only HDL cholesterol showed significant inverse association with $h s \mathrm{CRP}(\beta=-0.314, p=0.016)$ (Table 2).

\section{Discussion}

Dyslipidemia is a prominent one among the traditional biochemical risk factors of CVDs. Elevated TG, total cholesterol, and LDL cholesterol as well as decreased HDL cholesterol has been implicated with a variably increased risk of CVDs both in cross-sectional and prospective studies [27-29]. The nature and extent of dyslipidemia, however, may vary depending on the ethnic, cultural and environmental background of a particular population. For the management of lipid abnormalities, statin and fibrates are commonly used in our population. Some studies have identified residual CVD risk on therapy in different population [30]; no study has yet been carried out to explore the prevalence of lipid abnormalities on stable statin therapy in this population. In the present hospital based study on Bangalee population, 111 statin treated subjects were included. Among the study subjects most of them (83\%) were diabetic, $71 \%$ were hypertensive, $21 \%$ were obese and $15 \%$ had a habit of smoking.

In the study subjects, when analyzed single lipid abnormalities, LDL dyslipidemia was found to be the most prominent one (present in $57.66 \%$ subjects) followed by hypertriglyceridemia $(55.86 \%)$, HDL dyslipidemia (54.06\%), and hypercholesterolemia (20.72\%). When computing multiple combined lipid abnormalities, $19.82 \%$ subjects were found to have multiple combined dyslipidemia for HDL cholesterol, LDL cholesterol and TG. Moreover, 35.13\% had both elevated TG and elevated LDL cholesterol, $30.63 \%$ subjects had both low HDL cholesterol and elevated LDL cholesterol, and $21.62 \%$ had low HDL cholesterol and elevated TG.

Another major focus of this study was to investigate the extent
A

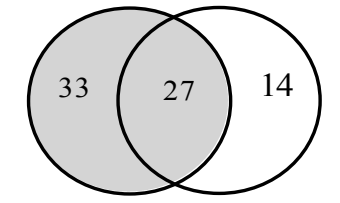

Low HDLC Elevated hsCRP
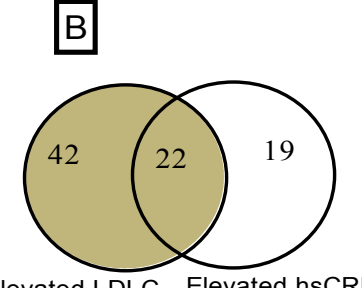

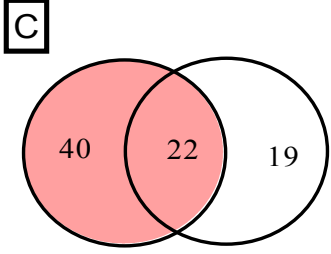

Elevated TG Elevated hsCRP

Figure 2: Distribution and proportion of combined single lipid abnormality and elevated hsCRP among the study subjects. 
Citation: Ferdousi F, Siddique MAH, Kamaluddin SM, Saiedullah M, Ali L (2015) Association of Lipid Abnormalities with High-Sensitivity C - reactive Protein in Patients Treated with Atorvastatin. J Diabetes Metab 6: 564. doi:10.4172/2155-6156.1000564

Page 4 of 5

of residual $h s \mathrm{CRP}$, a non-traditional risk factor of CVDs and the coexistence of $h s \mathrm{CRP}$ risk with individual lipid parameters. Higher $h s \mathrm{CRP}$ has been found to be associated with CVDs by a number of cross-sectional studies [31] and it has been reasonably confirmed as a predictor of CVDs by substantial volume of longitudinal data [32]. Its independent role, additional to the traditional risk factors, has also been substantiated and particularly its additive role with individual lipids, have also been published [33]. The mean value of $h s$ CRP was much higher than the upper cut-off limit $(3.0 \mathrm{mg} / \mathrm{l})$. Elevated $h s \mathrm{CRP}$ $(>3.0 \mathrm{mg} / \mathrm{l})$ was found to be high $(36.94 \%)$, followed by moderate risk $(33.33 \mathrm{mg} / \mathrm{l})$ and low risk for CVDs $(29.73 \%)$.

The coexistence of lipid abnormalities with elevated $h s$ CRP has also been explored. Elevated $h s \mathrm{CRP}$ was observed for low HDL cholesterol and elevated TG $(24.32 \%)$ but lower for elevated LDL cholesterol (19.82\%). In this study, multiple linear regression analysis showed that subclinical inflammation is inversely associated with HDL cholesterol $(\beta=-0.314, p=0.016)$ on adjusting confounding variables.

\section{Conclusion}

In conclusion, the elevated $h s$ CRP levels may reduce in patients treated with atorvastatin. The screening of patients with elevated CRP levels may identify patients who have an increased risk for cardiovascular events although the use of CRP levels as a predictor of cardiovascular events is not well defined for patients who already qualify for statin treatment because of lipid abnormalities. Further investigation is warranted to clarify the utility of routine CRP measurements and statin therapy in these patient populations.

\section{References}

1. Miranda JJ, Kinra S, Casas JP, Davey Smith G, Ebrahim S (2008) Noncommunicable diseases in low- and middle-income countries: context, determinants and health policy. Trop Med Int Health 13: 1225-1234.

2. Matheus AS, Tannus LR, Cobas RA, Palma CC, Negrato CA, et al. (2013) Impact of diabetes on cardiovascular disease: an update. Int J Hypertens 2013: 653789

3. AIGhatrif M, Kuo YF, Al Snih S, Raji MA, Ray LA, et al. (2011) Trends in hypertension prevalence, awareness, treatment and control in older Mexican Americans, 1993-2005. Ann Epidemiol 21: 15-25.

4. Carreiro-Lewandowski E (2004) Update on selected markers used in risk assessment for vascular disease. Clin Lab Sci 17: 43-49.

5. National Cholesterol Education Program (2001) Executive summary of the third report of the National Cholesterol Education Program (NCEP) expert panel on detection, and treatment of high blood cholesterol in adults (Adult Treatmen Panel III). JAMA 2001; 285:2486-2497.

6. Pichandi S, Pasupathi P, Raoc YY, Farook J, Ambika A, et al. (2011) The role of statin drugs in combating cardiovascular diseases. Int. J. Cur. Sci. Res. 1: 47-56

7. Nawrocki JW, Weiss SR, Davidson MH, Sprecher DL, Schwartz SL, et al (1995) Reduction of LDL Cholesterol by $25 \%$ to $60 \%$ in Patients with Primary Hypercholesterolemia by Atorvastatin, a New HMG-CoA Reductase Inhibitor. Arteriosclerosis, Thrombosis, and Vascular Biology 15: 678-682.

8. Kaptoge S, Di Angelantonio E, Lowe G, Pepys MB, Thompson SG, et al. (2010). Emerging Risk Factors Collaboration. C-reactive protein concentration and risk of coronary heart disease, stroke, and mortality: an individual participant metaanalysis. Lancet 375: 132-140.

9. Ridker PM, Brown NJ, Vaughan DE, Harrison DG, Mehta JL (2004) Established and emerging plasma biomarkers in the prediction of first atherothrombotic events. Circulation 109: IV6-19.

10. Pearson TA, Mensah GA, Alexander RW, Anderson JL, Cannon III RO, et al. (2003) Centers for Disease Control and Prevention; American Heart Association. Markers of inflammation and cardiovascular disease: application to clinical and public health practice. A statement for healthcare professionals from the Centers for Disease Control and Prevention and the American Heart Association. Circulation 107: 499-511.
11. Sabatine MS, Morrow DA, Jablonski KA, Rice MM, Warnica JW, et al. (2007) Prognostic significance of the Centers for Disease Control/American Heart Association high-sensitivity C-reactive protein cut points for cardiovascular and other outcomes in patients with stable coronary artery disease. Circulation 115 1528-1536.

12. Ridker PM, Cannon CP, Morrow D, Rifai N, Rose LM, et al. (2005) C-reactive protein levels and outcomes after statin therapy. N Engl J Med 352: 20-28.

13. Emerging Risk Factors Collaboration, Kaptoge S, Di Angelantonio E, Lowe G Pepys MB, et al. (2010) C-reactive protein concentration and risk of coronary heart disease, stroke, and mortality: an individual participant meta-analysis. Lancet 375: 132-140.

14. Balk EM, Lau J, Goudas LC, Jordan HS, Kupelnick B, et al. (2003) Effects of statins on nonlipid serum markers associated with cardiovascular disease: a systematic review. Ann Intern Med 139: 670-682.

15. Ridker PM, Rifai N, Pfeffer MA (1998) Inflammation, pravastatin, and the risk of coronary events after myocardial infarction in patients with average cholesterol levels. Cholesterol and Recurrent Events (CARE) Investigators. Circulation 98: 839-844.

16. Ridker PM, Rifai N, Clearfield M, Downs JR, Weis SE, et al. (2001) Measurement of $\mathrm{C}$-reactive protein for the targeting of statin therapy in the primary prevention of acute coronary events. N Engl J Med 344: 1959-1965.

17. Nissen SE, Tuzcu EM, Schoenhagen $P$ (2005) Reversal of Atherosclerosis with Aggressive Lipid Lowering (REVERSAL) Investigators. Statin therapy, LDL cholesterol, C-reactive protein, and coronary artery disease. N Engl J Med. 352: 29-38.

18. Ridker PM, Cannon CP, Morrow D, Rifai N, Rose LM, et al. (2005) C-reactive protein levels and outcomes after statin therapy. N Engl J Med 352: 20-28.

19. Morrow DA, de Lemos JA, Sabatine MS, Wiviott SD, Blazing MA, et al. (2006) Clinical relevance of C-reactive protein during follow-up of patients with acute coronary syndromes in the Aggrastat-to-Zocor Trial. Circulation 114: 281-288.

20. Genest J, McPherson R, Frohlich J, Anderson T, Campbell N, et al. (2009) 2009 Canadian Cardiovascular Society/Canadian guidelines for the diagnosis and treatment of dyslipidemia and prevention of cardiovascular disease in the adult - 2009 recommendations. Can J Cardiol 25: 567-579.

21. Fruchart JC, Sacks F, Hermans MP, Assmann G, Brown WV, et al. (2008) The Residual Risk Reduction Initiative: a call to action to reduce residual vascular risk in patients with dyslipidemia. Am. J. Cardiol. 102: 1K-34K.

22. Strang AC, Kaasjager HA, Basart DC, Stroes ES (2010) Prevalence of dyslipidaemia in patients treated with lipid-modifying drugs in the Netherlands. Part of the dyslipidaemia international survey. Neth J Med 68: 168-174.

23. Perloff D, Grim C, Flack J, Frohlich ED, Hill M, et al. (1993) Human blood pressure determination by sphygmomanometry. Circulation 88: 2460-2470.

24. World Health Organization (2006) Definition and diagnosis of diabetes mellitus and intermediate hyperglycemia: report of a WHO/IDF consultation.

25. Friedewald WT, Levy RI, Fredrickson DS (1972) Estimation of the concentration of low-density lipoprotein cholesterol in plasma, without use of the preparative ultracentrifuge. Clin Chem 18: 499-502.

26. Bland JM, Altman DG (1986) Statistical methods for assessing agreement between two methods of clinical measurement. Lancet 1: 307-310.

27. Sacks FM, Pfeffer MA, Moye LA, Rouleau JL, Rutherford JD, et al. (1996) The effect of pravastatin on coronary events after myocardial infarction in patients with average cholesterol levels. Cholesterol and Recurrent Events Trial investigators. N Engl J Med 335: 1001-1009.

28. Verschuren WM, Jacobs DR, Bloemberg BP, Kromhout D, Menotti A, et al (1995) Serum total cholesterol and long-term coronary heart disease mortality in different cultures. Twenty-five-year follow-up of the seven countries study. JAMA 274: 131-136.

29. Brewer HB Jr (2002) Rising to the challenge of the new NCEP ATP III guidelines: exceeding current therapeutic limitations. Am J Manag Care 8: S23-28.

30. Strang AC, Kaasjager HA, Basart DC, Stroes ES (2010) Prevalence of dyslipidaemia in patients treated with lipid-modifying drugs in the Netherlands. Part of the dyslipidaemia international survey. Neth J Med 68: 168-174.

31. Thakur S, Gupta S, Parchwani H, Shah V, Yadav V (2011) Hs-CRP - A potentia marker for coronary heart disease. Indian Journal of Fundamental and Applied Life Sciences 1: 1-4. 
Citation: Ferdousi F, Siddique MAH, Kamaluddin SM, Saiedullah M, Ali L (2015) Association of Lipid Abnormalities with High-Sensitivity C - reactive Protein in Patients Treated with Atorvastatin. J Diabetes Metab 6: 564. doi:10.4172/2155-6156.1000564

Page 5 of 5

32. Boehncke S, Salgo R, Garbaraviciene J, Beschmann H, Hardt K, et al. (2011) Effective continuous systemic therapy of severe plaque-type psoriasis is accompanied by amelioration of biomarkers of cardiovascular risk: results of a prospective longitudinal observational study. J. Eur. Acad. Dermatol. Venereol. 25: $1187-1193$
33. Ridker PM, Buring JE, Cook NR, Rifai N (2003) C-reactive protein, the metabolic syndrome and risk of incident cardiovascular events: an 8-year follow up of 14 719 initially healthy American women. Circulation 107: 391-397. 